\title{
The Availability and Accessibility of Sport Facilities and Adult Obesity in an Urban Environment
}

\author{
Muhammad Akmal Sallahuddin, M.A. Sallahuddin, Nur Faraheen Abdul \\ Rahman, N.F.A. Rahman.
}

Faculty of Medicine and Health Sciences, Universiti Sains Islam Malaysia, Kuala Lumpur, Malaysia

\begin{abstract}
Introduction: Ibnu Sina or Avicenna in "Asbab-e-Settah-e-Zaruriah" has pointed out that physical activity is one of the keys to a good health. However, urbanization has dawned upon the urban population and brought changes to their lifestyle. Among the change it brought is obesity. Obesity has been an epidemic with physical inactivity and unhealthy diet has taken the blame for this rising issue.
\end{abstract}

Objectives: As sports facilities plays an integral role in providing urban dwellers with facilities for physical activity, this scanning review investigates how availability and accessibility of sports facilities affect the participation of the urban community in sports, a form of physical activity.

Methodology: This article has been written based on papers found using Google Scholar from journals like Pubmed, Lancet, and others.

Results: There was a total of 100 articles found and only 53 fit the criteria of the search.

Conclusion: It can be concluded that most papers suggest that the participation of urban dwellers in a particular sport depends on the availability and accessibility of its sport facilities. However, from recent reading, there is no paper which concludes a direct relationship between the availability and accessibility of sport facilities and adult obesity in an urban environment.

The implication is that we hope is to further comprehend the role of sports facilities as a working strategy to reduce obesity in urban areas with the help of technology and gamification of sports.

Keywords: Adult Obesity, Sport Facilities, Sport Participation. 